\title{
Entre peregrinação, turismo e liminaridade: a busca por lugares
}

\author{
Between pilgrimage, tourism and liminarity: the search for places
}

\author{
Júlio Cézar Adam *
}

\begin{abstract}
Resumo
Este artigo reflete sobre o aspecto antropológico da peregrinação, o caminhar humano, como metáfora para a vida, como uma forma de se relacionar e entender a religião, a espiritualidade, a própria vida e o turismo como formas de peregrinação. Tomar-se-á para análise as peregrinações da tradição cristã, buscando entendê-las a partir da antropologia de Victor Turner, analisando a peregrinação como estado de liminaridade e liminóide. Concretamente se olhará o caso das Romarias da Terra no Brasil, como um exemplo de liminaridade/liminóide e communitas. Além disso, este artigo reflete sobre os "novos centros" de peregrinação, fora do âmbito religioso, como espaços da cultura pop ou a visita a locais turísticos e monumentos da memória social e cultural. O objetivo é entender para onde as pessoas têm peregrinado e qual o sentido dessas peregrinações. Neste deslocamento para fora do âmbito religioso, se pergunta se seria o turismo também uma forma de peregrinação. Ou faltaria ao turismo justamente o aspecto liminar, algo que poderia estar relacionado à análise de Bauman sobre o turista e o vagabundo? Suspeita-se que em um mundo globalizado os lugares perdem seu conteúdo e sua identidade. Pessoas passam pelos lugares, mas os lugares já não passam por elas. Com isso, o caminhar perde também sua função liminar.
\end{abstract}

Palavras-Chave: Peregrinação; Turismo; Liminaridade; Liminóide; Romaria da Terra

\begin{abstract}
This article reflects on the anthropological aspect of the pilgrimage, the human journey, as a metaphor for life, as a way of relating and understanding religion, spirituality, life itself and tourism as forms of pilgrimage. The pilgrimages of the Christian tradition will be analyzed, seeking to understand them of the anthropology of Victor Turner, analyzing the pilgrimage as a state of liminality and liminoid. Concretely we will look at the case of the Romarias da Terra in Brazil, as an example of liminality/ liminoid and communitas. In addition, this article reflects on the "new centers" of pilgrimage, outside the religious scope, as spaces of pop culture or the visit to tourist sites and monuments of social and cultural memory. The goal is to understand where people have pilgrims and what the meaning of these pilgrimages. In this displacement out of the religious scope, one wonders if tourism would also be a form of pilgrimage. Or would tourism lack precisely the preliminary aspect, something that could be related to Bauman's analysis of the tourist and the vagabond? It is suspected that in a globalized world, places lose their content and identity. People pass through places, but places no longer pass through them. With this, walking also loses its liminal function.
\end{abstract}

Keywords: Pilgrimage; Tourism; Liminality; Liminoid; Romaria da Terra

\footnotetext{
Artigo submetido em 29 de janeiro de 2018 e aprovado em 19 de abril de 2018.

* Doutor em Teologia pelo Universität Hamburg. Professor da Escola Superior de Teologia das Faculdades EST. País de origem: Brasil. Email: julioadam@est.edu.br
}

Horizonte, Belo Horizonte, v. 16, n. 49, p. 66-87, jan./abr. 2018 - ISSN 2175-5841 


\section{Introdução: Por que pessoas peregrinam?}

Seres humanos se põem em movimento, a caminho, em busca de um lugar ou algo que lhes falta. Mais do que apenas arejar as ideias ou exercício físico, para muitas pessoas, caminhar tem caráter simbólico, para outras, também caráter religioso. As peregrinações (etimologicamente, do latim per agros, isto é, pelos campos) têm este caráter simbólico, religioso, liminal (Victor Turner), no sentido de que a caminhada e os lugares por onde e para onde se caminha, tem um sentido maior, amplo e complexo, que extrapola o caminhar em si. O caminhar e a peregrinação tornam-se, assim, metáforas da busca humana por lugares. Exatamente este é objetivo deste artigo: refletir porque as pessoas se põem a caminho, seja em peregrinações, seja no turismo.

Assim como nas grandes religiões como o Islamismo, o Judaísmo, o Hinduísmo, também no Cristianismo, seja na tradição bíblica, seja na tradição da Igreja, há uma enormidade de relatos de peregrinação, procissões, ou então, a própria vida é entendida como um peregrinar entre o nascer e o morrer, uma jornada para a eternidade. A tradição judaico-cristã é rica na compreensão da vida e da fé em Deus como uma peregrinação, seja a peregrinação do êxodo, seja a trajetória de Jesus rumo à cruz do Gólgota, fundamento para as tantas tradições cristãs. O casal Turner, em seu estudo específico sobre a peregrinação, as classificam as em quatro tipos. 1) Peregrinações baseadas na autoridade, na evidência e na tradição disseminada do e a partir do seu fundador ou evento, como Jerusalém, para Cristãos e Judeus; Meca, para o Islã; 2) Peregrinações que surgem a partir do sincretismo entre antigas e novas religiões, como Chalma, no México; 3) Peregrinações que surgiram na Idade Média, na Europa, como Santiago de Compostela e 4) Peregrinações que surgiram no período moderno, muitas a partir do séc. XIX, baseadas na piedade popular e pessoal (TURNER; TURNER, 1978, p. 17s.). 
Neste último grupo, estão grande parte dos centros de peregrinação no Brasil, ligados à Igreja Católica Apostólica Romana: Nossa Senhora de Aparecida, em Aparecida/SP; Padre Cícero, em Juazeiro do Norte/CE; Bom Jesus da Lapa, na Bahia. E centros menores, como Nossa Senhora do Caravágio, em Farroupilha/RS e o Santuário do Pe. Reus, em São Leopoldo/RS e centenas de outros tantos. Em todos os casos, pessoas caminham em busca de algo maior que a própria caminhada. Baseados em algo extraordinário ocorrido naquele lugar, evento fundante emoldurado por outros relatos de milagres, visões, símbolos e estruturas oficiais e teológicas, pessoas buscam por um milagre, uma solução, uma iluminação na sua devoção, na sua fé e, concretamente, na vida, como tão bem descreve Steil:

Encenada e reencenada como um espetáculo onde o inalcançável e o possível, o visível e o invisível se interpelam numa trama urdida pela narrativa ficcional dos relatos orais e dos fragmentos escritos, a romaria abre os canais da sensibilidade e permite que os seus atores entrem em contato como sua própria subjetividade. Percorrendo o espaço mapeado pelos sinais dos lugares, os romeiros organizam sua subjetividade, projetando luz e sentido sobre sua experiência existencial e seu convívio social. (STEIL, 1996, p. 23).

Refletindo sobre a riqueza das tradições das peregrinações cristãs, pode-se observar o quanto a tradição protestante está desprovida da possibilidade de peregrinar. Para onde os protestantes peregrinam? Das muitas riquezas que os protestantes perderam com a Reforma, uma delas, sem dúvida, foi a capacidade e a possibilidade de peregrinar, rezar com os pés e o caminhar. Restringiram o peregrinar ao exercício racional teológico e às pequenas procissões no interior das igrejas, nos cortejos fúnebres, ou ainda, em forma de "turismo", nas visitas aos locais "sagrados", templos, ou ainda aos locais, casas, museus de personagens ou eventos importantes da Reforma. Seria a marcha para Jesus ou a visita ao Templo de Salomão uma expressão da saudade das peregrinações? Seriam estas novas manifestações uma expressão brasileira de uma peregrinação evangélica?

Mas não apenas de "peregrinação" cristã vive o ser humano. No Brasil, temos diversas peregrinações não institucionalmente religiosas como a instigante e 
profética Busca da Terra Sem Males (CLASTRES, 1978), dos índios tupi-guaranis, sendo a herotopia e a utopia nesse caso algo fundamental. Podemos pensar também se as migrações internas no país, para as grandes cidades, ou para novas áreas de colonização (como foram os deslocamentos para estados como Mato Grosso e Rondônia), ou as migrações para os grandes centros urbanos, tão bem retratadas nos livros Vidas Secas (Graciliano Ramos, 1938) e Morte e Vida Severina (João Cabral de Melo Neto, 1955).

No horizonte da globalização, do turismo e da secularização, podemos pensar ainda em outras formas de peregrinação. Situações marcantes deslocam pessoas a caminhar: locais, monumentos da memória são lugares que atraem milhares de pessoas, como museus, casas, monumentos, cidades. O estudo de Post, Molendijk e Kroesen (2011) sobre os espaços sagrados na cultura ocidental moderna, identifica não só um incremento nos antigos centros de peregrinação na Europa, como Santiago de Compostela, no norte da Espanha, mas também um incrível deslocamento de pessoas visitando - como turistas-peregrinos - locais de memória. Segundo os autores, um estudo de 2008, anualmente, um milhão de pessoas tem visitado a Casa de Anne Frank, em Amsterdam; 435 mil visitam anualmente Auschwitz-Birkenau, na Polônia; 7 milhões, Pear Harbour, no Havaí; 2 milhões e meio o Museu do Holocausto, em Washington; 3,6 milhões o Ground Zero, em Nova York; 400 mil, Robben Island, na Cidade do Cabo. Além de consumo turístico, o que mais estaria por detrás de tamanha mobilidade humana? Por que milhares de pessoas caminham até estes locais? Com certeza trata-se de alguma maneira deixa-se mover pelo local que é visitado e a memória que ele condensa. Os autores consideram que todos estes locais de visitação estão também marcados pelo rito, pelo aspecto sagrado e, também, pelo religioso.

Nesse sentido, pode-se perguntar, além dos centros de peregrinação da Igreja Católica, como espaços religiosos institucionais de peregrinação, quais são os outros locais de peregrinação do Brasil, locais do resgate da memória, da construção de narrativas populares e de imaginários sociais? Quais os locais de 
memória do terrível tráfico e comércio de escravos, ou da memória da ditadura, p. ex. Mais recentemente, locais de tragédias tornam-se locais para onde as pessoas se movem, como o local da queda do avião da Tam, em São Paulo/SP, ou a Boate Kiss, em Santa Maria/RS, onde, inclusive, monumentos são construídos. Mesmo assim é de se perguntar, se temos tantas tragédias humanas, por que não temos mais locais de memória e de peregrinação social e cultural.

Por fim, a indústria do turismo também tem investido nesta disposição e necessidade humana de se colocar a caminho. A palavra "turismo" tem a sua origem no francês tour, termo que equivale a circuito, volta ao redor, volta, ou do termos tourner, fazer a volta, termos que, por sua vez, tem sua raiz no latim tornare, girar um torno, fazer dar a volta, ou ainda, polir. São muitos os locais, em todo o mundo, para onde as pessoas "peregrinam" ou "dão a volta" como turistas: praias, reservas naturais, cidades que se destacam por sua beleza e história, construções, etc. Também locais onde ídolos viveram, como Elvis Presley, em Memphis, estúdio de gravação dos Beatles, em Londres, ou a fictícia casa do Sherlock Homes, também em Londres, ou ainda lugares onde filmes foram filmados, como Senhor dos Anéis, na Nova Zelândia ou Game of Thrones, na Irlanda do Norte. Interessante que estes últimos locais se tornam relevantes através de eventos fictícios e através da mídia (literatura, música e cinema). Ou ainda, lugares onde temporariamente um ídolo pop se encontra. Pessoas "dão uma volta” para assistir a shows de seus ídolos como Madonna, a banda U2, entre tantos outros exemplos. Por que pessoas se põem a caminho? O que elas buscam individualmente e coletivamente? Qual a relação entre peregrinação com a vida cotidiana e a sociedade? Seria o turismo uma nova forma de peregrinação?

Podemos responder a estas questões de muitas maneiras. Neste artigo, propõe-se pensar a peregrinação a partir do rito como um conceito analítico. Aprofundando a compreensão, busca-se alguma orientação na teoria antropológica de Victor Turner, sobre liminaridade e liminóide. Em seguida, se busca aplicar a teoria da liminaridade ao exemplo das Romarias da Terra e, por fim, busca-se 
retomar a questão do turismo e refletir em que medida também o turismo - qual turismo? - pode ser uma forma liminal de peregrinação.

\section{Peregrinação como rito: liminaridade e liminóides (Victor Turner)}

Victor Turner foi um eminente antropólogo britânico (1920-1983) (TURNER, 1985). Turner é conhecido principalmente por suas teorias no campo da antropologia social, em especial a influência dos dramas sociais, dos processos rituais e das experiências e performances rituais no desenvolvimento e na continuidade da vida social. Suas teorias sobre drama social, processo ritual, liminaridade, communitas, liminóide, experiência e performance ritual, entre outras, versam sobre as mais variadas dimensões da ritualidade humana (ROSA, 2017, p. 21).

Estudando uma pequena tribo chamada Ndembu, no nordeste da Zâmbia, o antropólogo desenvolveu sua noção de liminaridade. Através dela, o autor mostra que a sociedade Ndembu caracteriza-se por ser uma mistura de fenômenos estruturais, no âmbito político, jurídico e econômico e fenômenos contraestruturais, no âmbito das artes, religião, esportes. Exatamente neste segundo âmbito, dos fenômenos contraestruturais, é que ocorre o que ele chamou de liminaridade.

Turner chega a esta noção, analisando os ritos tribais a partir do seu lado interior, ou seja, a partir daquilo que o rito desencadeia em seus participantes, a partir do processo ritual das pessoas envolvidas no rito. Na sua análise, o rito não está separado da vivência concreta e cotidiana das pessoas, mas sim, está em relação direta com a crise da vida e da sociedade (TURNER, 1989, p. 17, 51). O rito irá oportunizar um momento de interrupção e ruptura em meio a situação vivencial, durante o qual se desenvolve um drama social. Turner

[...] adapta o modelo trifásico de van Gennep - separação (séparation), transição (marge) e agregação (aggrégation) -, originalmente relacionado com ritos de iniciação, e desenvolve dali uma tese ritual como intenção de 
princípio. Para ele todas as ritualizações têm inerentes um momento em que a transição de limite é possibilitada. Turner modifica o conceito do 'limite'. Ele divisa como que por um vidro de aumento o lugar de passagem entre as fases da vida, os sistemas simbólicos e os nexos comunicativos, e descobre na linha divisória um espaço de transição do limite. Ele o designa como espaço da liminaridade. Essa experiência liminar surge no processo de uma recepção. (BAHR, 1998, p. 146).

Nessa fase de liminaridade, "o ritual não apresenta tanto o mundo, mas fundamenta e cria o mundo" (JENNINGS, 1998, p. 162), o que mostra o quanto o rito está relacionado ao drama social como um todo.

O espaço de transição não é um vácuo. Como espaço, ele se encontra elaborado e organizado. Simultaneamente, entretanto, abre-se um espaço livre, um interlúdio da nova combinação e das experiências interpretativas. Pois é exatamente assim que surge significação. O espaço de transição de limite abre uma área de construção e um tempo interino (BAHR, 1998, p. 147).

Decisivo para Turner torna-se este momento específico do ritual, i.e., lá onde se dá a transição, a passagem, numa condição ou num espaço que se encontra no limite. O autor vê neste específico, na transição do limite, algo que, ao mesmo tempo, delineia duas formas de vida na sociedade: estrutura e antiestrutura. Pois a sociedade para Turner não é nenhum objeto ou estado, mas oscila num permanente processo entre estrutura e antiestrutura ou communitas.

É como se aqui surgissem dois modelos principais de relacionamentos sociais humanos, que subsistem lado a lado e se alternam mutuamente. $\mathrm{O}$ primeiro modelo apresenta a sociedade como sistema estruturado, diferenciado e muitas vezes subdividido hierarquicamente em posições políticas, jurídicas e econômicas, com muitas formas de avaliação, que dividem as pessoas no sentido de um "mais" ou "menos". O segundo modelo, claramente reconhecível na fase de liminaridade, é o da sociedade como comunidade não estruturada ou estruturada rudimentarmente e parcialmente não diferenciada, comitatus, ou também como comunidade de iguais, que se submetem conjuntamente à autoridade geral dos ritualmente mais idosos (TURNER, 1989, p. 96).

Segundo sua teoria, no rito ocorre a simplificação ou até mesmo a "eliminação" momentânea da ideia de estrutura e, através desta experiência, crises e conflitos individuais e/ou sociais são reparados. No momento em que algum 
problema se instala na vida individual ou social, os ritos "aparecem” para tratá-lo, explorando a dimensão simbólica da realidade social e colocando as pessoas diante das causas do problema. As práticas rituais garantem, assim, o equilíbrio e o bemestar da vida social, cumprindo um papel restaurador e terapêutico.

Para Turner, portanto, o rito possibilita viver o drama social e representar o jogo social. O rito também tem a função de expressar um meta-comentário social segundo normas determinantes e por meio de uma sequência ordenada, de onde as pessoas envolvidas (passantes) emergem renascidos, novamente integrados e transformados. Esse novo é possível graças à força simbólica e ambivalente da passagem

$\mathrm{Na}$ "fase de transição" média, o sujeito ritual (o "passante") é caracterizado por ambiguidade; ele atravessa uma área cultural, que apresenta poucas ou nenhuma das características do estado passado ou futuro. [...] Seres de transição não estão nem aqui nem acolá, eles não são nem uma nem outra coisa, mas se encontram entre as posições fixadas pela lei, pela tradição, pela convenção e pelo cerimonial. Muitas sociedades que ritualizam passagens sociais e culturais dispõem, por essa razão, de uma multiplicidade de símbolos que expressam essa ambiguidade e indeterminação do estado de transição. Dessa forma, o estado de transição muitas vezes é equiparado com a morte, a existência no útero, com invisibilidade, escuridão, bissexualidade, com local selvagem e com eclipse solar ou lunar. (TURNER, 1989, p. 94s.).

Liminaridade tem, também, uma relação estreita com o poder, uma vez que a fase de liminaridade relativiza os poderosos da estrutura e dá força aos impotentes, algo que Turner designa de força ritual dos fracos (TURNER, 1989, p. 101-103) e que também se encontra presente em outras formas de manifestações culturais (p. 107). Um exemplo para isso, Victor e Edith Turner, trazem em seu estudo sobre o santuário de Guadalupe, no México, no qual registraram as palavras de um romeiro que dizia ter visto na peregrinação "a única sociedade sem classe possível (...). Um triunfo da única igualdade real da graça e do espírito" (TURNER; TURNER, 1978, p. 97). A recorrência deste sentimento que parece romper com as fronteiras de classe, de idade e de sexo estabelecidas pelas estruturas sociais, está na origem da ideia de communitas com a qual os Turner têm procurado explicar as peregrinações (STEIL, 1996, p. 66). 
Após ter desenvolvido o conceito de liminaridade, característico em sociedades tribais, Turner passou a refletir sobre os meios de resolução de conflitos das sociedades industriais, tecnológicas e globalizadas. Foi a partir desse novo contexto que o autor desenvolveu uma variação do conceito de liminaridade, os "liminóides". Os fenômenos liminóides ou quase-liminares se caracterizam como derivados da liminaridade das sociedades antigas, tribais e tradicionais. Para ele, em nossas sociedades a liminaridade está fragmentada em múltiplos gêneros de performances culturais, como o teatro, a música, o cinema, os esportes, etc. (ROSA, 2017, p. 5). Turner coloca as peregrinações dentro deste novo tipo de liminaridade, como um liminóide.

Ou seja, as peregrinações, semelhante ao teatro, o lazer, o esporte e o turismo, seriam para Turner momentos rituais de quase-limaridade, momentos liminóides. Além de estarem fragmentados, na experiência liminóide a pessoa é livre para participar ou não. Mesmo assim, também os liminóides possibilitam descobertas e iluminação, uma experiência com a antiestrutura da sociedade, uma forma de quase-communitas, pode-se dizer. A quase-liminaridade também provoca ambivalência e, além disso, uma espécie de ausência de status, uma mescla de humilhação e santidade ao mesmo tempo, num processo dialético (TURNER; TURNER, 1978, p. 253s.).

Com base em Turner, podemos dizer que as peregrinações existem nas "brechas na estrutura social e eclesial, se infiltram na marginalidade das periferias da estrutura e na inferioridade abaixo da estrutura. Como communitas, transgridem ou abolem as normas que regem relações estruturadas e institucionalizadas, e acompanhada da experiência de força sem precedentes." ( TURNER, 1989, p. 1250).

A peregrinação, então, tem algum atributo de liminalidade em ritos de passagem: libertação da estrutura mundana; homogeneização do status; simplicidade de vestimenta e comportamento; communitas; provação; reflexão sobre o significado dos valores religiosos e culturais básicos; Ratificação de correspondências entre paradigmas religiosos e experiências humanas compartilhadas; emergência da integralidade 
pessoal a partir de múltiplos personagens; O movimento de um centro mundano para uma periferia sagrada, a qual, de repente e transitoriamente, torna-se central para o indivíduo, um axis mundi de sua fé; O próprio movimento, um símbolo de communitas, que muda com o tempo, contra o estabelecido, que representa a estrutura; individualidade colocada contra o meio institucionalizado; e assim por diante. Mas, uma vez que é voluntário, não um mecanismo social obrigatório para marcar a transição de um indivíduo ou grupo de um estado ou status para outro dentro da esfera mundana, a peregrinação talvez seja melhor definida como "liminoide" ou "quase-liminar", em vez de "liminar", no sentido pleno de Van Gennep. (TURNER; TURNER, 1978, p. 34s.).

\section{Romaria da Terra: busca de lugares aos quais pertencer}

Romaria da Terra é uma peregrinação engendrada no Brasil. Nela se pode ver, claramente, muitos, senão todos os aspectos liminais que, segundo Turner, caracterizam uma peregrinação. Além disso, a Romaria da Terra, como peregrinação autóctone, politicamente e criticamente pensada (invenção militande, segundo Carlos Alberto Steil), como resposta aos deslocamentos humanos e à exclusão geográfica (METTE, 2010), é pertinente de ser analisada, no contexto deste artigo. As mesmas perguntas levantadas no início do artigo, podemos fazer aqui: Para onde peregrinam os romeiros da terra? O que buscam? Que tipo de limaridade/liminoide e communitas estão presentes na Romaria da Terra? O que a romaria tem de turismo?

A Romaria da Terra surgiu na região sul do Brasil no período da ditadura militar (1964-85). Estava diretamente relacionada à então nascente Teologia da Libertação, articulando uma teologia a partir da injustiça social no campo. Esta peregrinação da terra surge em apoio Pobres da Terra (MAY, 1986), ou seja, pessoas migrantes, posseiros, pequenos agricultores, sem-terras, assalariados rurais, atingidos por barragens povos indígenas e quilombolas. Esta forma autóctone de peregrinação misturava elementos das passeatas de protesto das romarias tradicionais e as novas formas de celebração e de espiritualidade das comunidades de base (CEBs). Claramente, a peregrinação está marcada pela combinação entre religiosidade popular e política. De forma rápida as Romarias da 
Terra vão ganhando espaço e expressão em todo o país. Esta análise concentra-se, especialmente, nas romarias do estado do Paraná, no sul do Brasil (ADAM, 2012).

O fenômeno das Romarias da Terra pode ser entendido somente a partir do conflitivo pano de fundo de luta pela terra, um impasse até hoje não resolvido pela sociedade brasileira. A concentração de terra nas mãos de alguns joga milhares de famílias em um drama social de exclusão que se estende pela realidade agráriaurbana do país, até hoje. A busca por espaço aos quais se pertence (WESTHELLE, 1990, p. 255) está claramente na base da Romaria da Terra, como um paradigma. Por isso ela assim se chama: Romaria da Terra. Parece ser exatamente essa busca pelos lugares aos quais pertencer que a experiência liminal irá possibilitar aos participantes (passantes) de uma Romaria da Terra.

Espaço aqui abrange tanto os lugares concretos, onde as pessoas vivem, a cultura, os costumes, recursos naturais, como rios e nascentes, como também o próprio corpo, a vida pessoal, algo que Tuan, no seu rico estudo sobre os lugares como espaço de experiência e de intimidade: "Lugar é um pausa no movimento. [...] A pausa permite que uma localidade se torne um centro de reconhecido valor." (TUAN, 1983, p. 153) Exatamente nesse sentido, quando se fala de lugar na romaria se está falando do próprio chão, o lugar, a terra, onde se vive, se planta, se tira o sustento da família e do corpo, onde se estabelece relação com a natureza, com Deus, com outras pessoas e onde a cultura é construída. Esta procura por espaço em forma de lugares aos quais se pertence marca profundamente a romaria. Estes espaços e lugares concretos, tem clara densidade místico-religioso. Espaço, lugar e terra têm dimensões profundamente simbólicas, como aponta Westhelle:

[...] a luta pela terra não é apenas uma luta particular para a transformação social, não é apenas estratégia dentro de um projeto histórico (sociedade socialista, reino, etc.). Seu objetivo é a libertação do espaço na forma de lugares aos quais se pertence. Esta libertação do espaço é mais do que um meio. Já é um fim. É isto que diz a palavra de ordem: 'Terra é Vida'. [...] A dificuldade que enfrentávamos era [...] falar [...] que o objeto mesmo desta luta, a terra, o espaço, os lugares ocupados, os acampamentos, tenha densidade teológica; que o espaço pelo qual se dá a luta seja, de alguma forma, qualificado pelo sagrado. (WESTHELLE, 1990, p. 255). 
Não esquecendo que centenas de lutas de resistência em toda essa geografia foram organizados pelos grupos e organizações de campesinos, indígenas e negros a partir de motivos simbólicos, místico-religiosos (SOUZA; CARAVIAS, 1990, p. 62). Por isso, diferente das outras peregrinações, em muitos casos os peregrinos da terra não caminham para um santuário, mas sim para os lugares e centros que concretamente ou simbolicamente são vitais, a terra. Famosa é a frase: Terra é vida! Tem-se aqui, portanto, uma importante confluência entre a busca pelo centro-lá-fora, de Turner; o sagrado, típico das peregrinações religiosas, como espaço liminal; mas, ao mesmo tempo, temos algo dos lugares turísticos de resgate da memória, de Post, e ainda o elemento político do protesto, característico das passeatas.

A Comissão Pastoral da Terra (CPT), organização da Igreja Católica, assume muito cedo a responsabilidade pelas organizações e celebrações da Romarias da Terra. Pode-se dizer que a estrutura litúrgica dessa peregrinação é, em nível de Brasil, muito parecida. Todo o labor litúrgico está na prática das romarias do Paraná sob responsabilidade de pessoas não-teólogas ou liturgistas, pessoas não ligadas ao clero. Pode-se dizer que toda a liturgia é elaborada, moldada, concebida, conduzida e, posteriormente, avaliada em equipes compostas por agentes de pastoral e pelos próprios participantes. No caso das romarias no Paraná, em geral, pode-se estruturá-la em três grandes partes, algo que muito claramente pode ser relacionado com os três estágios do drama ritual tomado de Van Gennep, por Turner: 


\begin{tabular}{|c|c|c|}
\hline $\begin{array}{l}1 \text { Concentração inicial e } \\
\text { abertura da romaria. }\end{array}$ & $\begin{array}{l}2 \text { A procissão ou } \\
\text { caminhada. }\end{array}$ & 3 A festa final. \\
\hline $\begin{array}{l}\text { As caravanas provenientes } \\
\text { dos mais diferentes locais } \\
\text { encontram-se no local da } \\
\text { abertura. As pessoas são } \\
\text { recebidas com café da manhã; } \\
\text { Em seguida, inicia a liturgia de } \\
\text { abertura da romaria e } \\
\text { saudação dos/as romeiros/as, } \\
\text { organizações e comunidades. } \\
\text { Cria-se um corredor entre } \\
\text { os/as romeiros. Um caminhão } \\
\text { com sistema de som é usado } \\
\text { como palco. Fazem parte da } \\
\text { liturgia de abertura: a } \\
\text { "saudação da mãe-terra"; } \\
\text { recepção do símbolo da } \\
\text { romaria; memória das } \\
\text { romarias passadas; recepção } \\
\text { da bíblia e da cruz da romaria; } \\
\text { momento de protesto em } \\
\text { relação ao lugar onde o povo se } \\
\text { reúne nessa primeira parte. }\end{array}$ & $\begin{array}{l}\text { Após o protesto é hora de } \\
\text { ir em busca de outro } \\
\text { lugar. Os/as romeiros/as } \\
\text { saem em busca desse } \\
\text { outro lugar; a procissão é } \\
\text { marcada por estações de } \\
\text { memória e protesto. } \\
\text { Durante a caminhada } \\
\text { oram, cantam e } \\
\text { expressam gritos de } \\
\text { guerra. Leva-se na } \\
\text { procissão a bíblia, a cruz } \\
\text { e os símbolos } \\
\text { apresentados na } \\
\text { primeira parte. Um } \\
\text { caminhão com som } \\
\text { conduz a procissão. }\end{array}$ & $\begin{array}{l}\text { Após a procissão chega-se } \\
\text { a um novo lugar, onde o } \\
\text { povo se reúne para } \\
\text { almoçar. Em seguida, } \\
\text { inicia-se a liturgia final de } \\
\text { celebração da esperança, } \\
\text { cujos elementos são: } \\
\text { plenária para discursos e } \\
\text { apresentações artísticas; } \\
\text { anúncio das conquistas da } \\
\text { luta do povo; leitura } \\
\text { bíblica que anima a luta e } \\
\text { fortalece a esperança. Esse } \\
\text { último momento tem } \\
\text { caráter festivo com comida } \\
\text { e bebida, dança e canto } \\
\text { típicos do local; Antes da } \\
\text { partida se estabelece um } \\
\text { compromisso político- } \\
\text { social; recebe-se a benção } \\
\text { final. }\end{array}$ \\
\hline
\end{tabular}

Variações litúrgicas estão a cargo de cada CPT-Regional e da equipe litúrgica responsável. Se o trabalho da CPT tem uma relação mais próxima com a diocese local ou com um santuário, a romaria aproveita-se de elementos das romarias tradicionais e/ou, no mínimo, das tradições do catolicismo popular local. Então, normalmente, é celebrada uma missa no final da romaria. No caso da Romaria da Terra no Paraná, não se peregrina para um centro religioso, como um santuário, mas sim para locais importantes para o resgate da memória - local onde viveu uma liderança social importante para a região - ou para vislumbrar alternativas sociais - uma cooperativa, p.ex.

Como as romarias tradicionais, as Romarias da Terra reúnem um grande número de pessoas, motivadas através dos trabalhos da CPT: grupos agricultores/as ligados ao Movimento Sem-Terra (MST); Organizações de Pequenos-Agricultores; organizações de posseiros, boias-frias, agricultura familiar 
ou outras formas de organização no campo; povos indígenas; comunidades de base (CEBs); grupos de negros e grupos de mulheres; ou simplesmente pessoas, que estão identificadas com a "igreja dos pobres", como as CEBs nas cidades, pastoral operária e dos jovens; sindicatos, partidos e ONGs, entre outros, podendo somar entre 5 a 70 mil pessoas. A duração de uma romaria é diferente em cada lugar. Elas duram normalmente um dia, tendo havido romarias que duraram de três a sete dias e, até mesmo, no passado, durante três semanas.

As pessoas participantes organizam-se em grupos, caravanas e em comunidades, alguns meses antes da peregrinação, a partir de material distribuído pela CPT, em forma de cartilha, cartazes, etc., em torno ao tema escolhido. As pessoas participantes são militantes ativistas, que geralmente participam de passeatas e protestos políticos, já tendo vivido na pele a repressão por parte do governo, enfrentado a polícia e milícias privadas, já tendo sido presos e/ou perdido companheiros/as, mortos/as em confrontos e emboscadas. Esta experiência de frequente enfrentamento sociopolítico tem se tornado, de alguma forma, parte da cultura do movimento em torno à Romaria da Terra. Política, resistência e luta devem ser lidas, neste contexto, como sinônimos, onde os próprios envolvidos definem suas vidas como uma grande luta. Mesmo com todo este caráter militante, as romarias do Paraná tem também um elemento turístico: visitar uma cidade, uma organização, um determinado lugar diferente, a cada ano.

No horizonte das pessoas participantes não está um projeto sociopolítico claramente definido, mas sim uma visão política, uma forma de viver na terra que vai se definindo, ao longo de um processo, um modelo rural alternativo à agricultura capitalista-globalizada. As alternativas sociopolíticas têm maior relação com experiências concretas vividas nas organizações locais, do que com um projeto político no vácuo das ideologias. Sem dúvida, um modelo de sociedade está como pano de fundo do sonho e da visão, mas este pano de fundo surge das vivências e experiências - boas e ruins- no cotidiano da luta, no ensaio da esperança. A peregrinação expressa muito claramente que o modelo sociopolítico-econômico 
que aí está não serve. Vê-se aqui, muito claramente aquilo que Turner define como communitas, uma communitas permanente, criada através da experiência ritual liminóide da contraestrutura.

Esta communitas se reforça através de elementos místico-utópicos pertencem também a este pano de fundo, assim como, elementos de uma teologia da terra, ambos ricamente ritualizados nas romarias da terra: a terra pertence ao Deus-Criador e a concentração de terra não faz parte da sua vontade. Assim como no testemunho bíblico - do êxodo passando pelos profetas e por Jesus Cristo - Deus assume o partido dos pequenos, se identifica com eles e se faz presente nas suas histórias e lutas. Na romaria, Deus mesmo coloca-se a caminho com o povo. Ao mesmo tempo, elementos racionais e críticos, como a conscientização (FREIRE, 1979) e a união, são combinados com a mística, como métodos de organização diante da injustiça social, na articulação de uma teologia contraestrutural, onde Deus toma partido tem grande importância para o contexto de procura de espaço, no qual os participantes se movem.

Romaria da Terra é uma peregrinação e, como tal, permite uma experiência de liminaridade/liminóide e, consequentemente, uma experiência de communitas, ou seja, daqueles que viveram uma experiência liminal. Visitar um lugar significa colocar-se a caminho, se movimentar, ir e desinstalar-se. Pode-se dizer que cada Romaria da Terra cria, através do movimento, os lugares existentes e sonhados. Movimento, lugares e pessoas são essenciais de toda romaria. Quatro formas de movimento caracterizam uma romaria: 1) Deixar a casa, o grupo, organização, a comunidade e peregrinar até o local onde irá acontecer a romaria 2) A procissão no local da romaria (segunda parte da liturgia, como visto acima), deixando o local de concentração e de protesto, na procura de um outro lugar, novo e especial, um lugar para a festa; 3) O andar ritual, principalmente presente na primeira parte litúrgica, através do qual pessoas ritualizam e apresentam algo caminhando através de um corredor em meio ao público, indo em direção ao palco (geralmente um caminhão com som que serve como palco) e de lá retornam para o meio do público 
reunido novamente; 4) O voltar para casa e para as localidades ao final da romaria. Todos estas passagens e movimentos rituais podem ser entendidos, a partir de Turner, como momentos que oportunizam a experiência liminóide.

Através destes movimentos ou caminhadas ritualizadas revive-se a paradigmática "procura de espaço" tão presente no cotidiano das pessoas e de suas organizações e suas comunidades. As autoestradas e rodovias - lugares do provisório, lugar de passagem ou não-lugares, mas também lugar de protesto e de passeata, ou lugar de sobrevivência, em cujas margens índios, posseiros e pequenos agricultores desapropriados de seus lugares acampam - são tomadas na romaria como símbolo de procura e de resistência. Estradas fazem parte do cotidiano de muitos romeiros, e representam sua não-situação, sua condição limítrofe de despossuídos de lugares. As estradas não são lugares (AUGÉ, 200o) para estabelecer-se, "pois aqui não há pátria, mas sim elas impulsionam as pessoas a seguir adiante.” (BOLLNOW, 1963. p. 106). A diferença nas romarias é que as estradas e os caminhos conduzem a um bom fim, conduzem à festa - espaço liminoide e da communitas -, onde os sinais do Reino de Deus são vistos e provados em partes, uma clara experiência liminal e de communitas, no sentido de Turner.

A Romaria da Terra cria e reforça, assim, a communitas e a antiestrura, pelo rito e a liminaridade que proporciona. Em uma romaria, os romeiros não só caminham ou visitam um lugar, ou se conscientizam de suas lutas políticas e sua militância, mas sim, experimentam na liminaridade e liminoide, na ambiguidade do rito, a possibilidade de mudança de status, a atualização das memórias subversivas (memórias perigosas, Metz), o encontro simbólico com o passado e o futuro, a festa lúdica, utópica e carregada de esperança das mesas fartas, a terra e a água livres, de modo que após a romaria as pessoas já não são as mesmas, experimentaram um outro lugar e voltam para casa alimentadas pela possibilidade do subversivamente outro. 


\section{Fazer turismo: uma forma liminal de peregrinação?}

Seria o turismo uma forma de peregrinação? Sem dúvida, peregrinações tem muito de turismo e o turismo absorveu muito das peregrinações. Agências de viagem organizam peregrinações e viagens com promessas de ruptura com cotidiano, descanso, diversão, convivência, contato com o outro, com o diferente, com uma nova experiência, etc. Alguns desses elementos também pertencem ao campo do sagrado e do religioso. Interessante que no âmbito do turismo aparecem lugares para os protestantes "peregrinarem": cidades da Reforma, locais onde líderes como Martin Luther-King esteve, o campo de concentração onde Dietrich Bonhoeffer foi executado, cemitérios ou locais onde figuras importantes estão sepultadas, etc. Ensaiando uma resposta para a pergunta acima formulada sobre as formas de peregrinação protestantes, pode-se dizer que os protestantes não peregrinam, mas fazem turismo.

O estudo sobre espaços sagrados na cultura ocidental moderna, que vimos acima (Post, Molendijk e Kroesen), considera que o turismo, seria, sim, uma forma moderna de "peregrinação". Para Paul Post, entender o turismo e o turista é algo complexo (POST, 2011, p. 47), por sua diversidade, mas também por sua associação com consumo e comercialização. Para o autor, turismo tem a ver com experiência, com o encontro com o outro, o não-familiar, o estranho e, ao mesmo tempo, consigo mesmo (POST, 2011, p. 48). Além de proporcionar recreação, diversão, experiência, também atinge a pessoa na sua dimensão existencial, na busca por descobrir seu lugar no mundo e sua própria identidade, como bem aponta Yázigi, em seu crítico estudo sobre a autenticidade do turismo hoje:

[...] os turistas não são idiotas submissos aos agentes comerciais que inventam produções: eles desejam crer que tudo o que vivem seja orientado por valores estéticos e humanos e não uma troca econômica, porque têm necessidade de imaginar suas vidas; de fabricar suas próprias imagens. Isso conferiria um sentido. (YÁZIGI, 2009, p. 21).

Exatamente neste aspecto, Post estabelece relação com a compreensão de Turner (1973) sobre as peregrinações. Peregrinações possibilitam a seres humanos 
encontrar orientação fora de si mesmo, fora do cotidiano, num heterotopos, em um centro que está fora, no outro.

\begin{abstract}
A tipologia baseia-se na oposição entre um "centro", por um lado, a vida cotidiana, o padrão de vida normal e comum, e um "centro-lá-fora", no outro, i. e., o ponto de orientação fora do centro. No sentido geral e fundamental, a experiência turística envolve o duplo processo de alienação do padrão de vida cotidiana e a atração pelo "outro". Vale ressaltar que, neste contexto, é feito pouca referência ao fato de que este mesmo padrão antropológico básico se encontra não apenas na rica tradição da literatura de peregrinação, mas também na pesquisa sobre rito e festa. (POST, 2011, p. 48s.).
\end{abstract}

Assim como na peregrinação, o turismo está muito relacionado ao que Turner chama de liminóide, pela fragmentaridade que representa. Talvez o turismo de consumo, diferente do turismo a locais de resgate da memória, como a casa de Anne Frank, ou a locais de cunho histórico e cultural, como museus ou memoriais, ou de certa adesão pessoal e coletiva, como locais relacionados a ídolos e personalidades de referência, esteja mais caracterizado pela fragmentaridade e seja

mais complexa a comparação com uma peregrinação. Pode-se aqui perguntar se o turismo de consumo possibilita de fato uma experiência liminal, como viu-se acima.

O turismo de consumo encontra sua crítica no que Bauman escreve sobre turistas. No seu livro O mal-estar da pós-modernidade (1998), refletindo sobre a desestruturação do espaço e do tempo na pós-modernidade, fenômeno no qual a própria fixação de uma identidade é evitada, utiliza o turista e o vagabundo como metáforas para explicar a situação do ser humano contemporâneo.

Os turistas que valem o que comem são os mestres supremos da arte de misturar os sólidos e desprender o fixo. Antes e acima de tudo, eles realizam a façanha de não pertencer ao lugar que podem estar visitando: é deles o milagre de estar dentro e fora do lugar ao mesmo tempo [...] É como se cada um deles estivesse trancado numa bolha de osmose firmemente controlada. (BAUMAN, 1998, p.114). 
Mesmo que Bauman não esteja refletindo aqui sobre peregrinação e a possibilidade de uma experiência liminal, parece haver uma clara diferenciação entre a experiência do peregrino da do turista. "A peculiaridade da vida turística é estar em movimento, não chegar. Ao contrário daqueles seus antecessores, os peregrinos, as sucessivas escalas dos turistas não são estações pelo caminho, uma vez que não há nenhum objetivo que lhes acene, no fim das viagens da vida, que pudesse convertê-los em estações.”(BAUMAN, 1998, p. 114s.). Turistas caminham por lugares; peregrinos, os lugares caminham por eles, poderia-se dizer, algo semelhante com o que se refletiu sobre a relação dos pequenos agricultores com a terra: terra como lugar ao qual se pertence (Westhelle).

E mesmo assim, segundo Bauman, a "vida do turista não é um mar de rosas". Os turistas também estão em busca de algo, uma nostalgia por um mundo mais aberto e amplo: "Eles partem porque acham o lar maçante ou não suficientemente atrativo, demasiadamente familiar e contendo demasiadamente poucas surpresas, ou porque esperam encontrar em outro lugar uma aventura mais excitante e sensações mais intensas do que a rotina doméstica é capaz de transmitir."(BAUMAN, 1998, p. 116). Ou seja, há uma busca, uma inquietude, uma nostalgia que coloca o turista em movimento, indo ao encontro da proposta de Post e Turner.

Bauman ainda usa a figura do vagabundo como metáfora complementar ao turista para falar da condição do ser humano pós-moderno. Diferente do turista que pensa ser livre para visitar o mundo, o vagabundo está sujeito à abertura do mundo, estando em todos os lugares não por opção, mas por necessidade. Segundo ele,

Os vagabundos [diferente dos turistas], sabem que não ficarão por muito tempo, por mais intensamente que o desejem, uma vez que em lugar nenhum em que parem são bem-vindos: se os turistas se movem porque acham o mundo irresistivelmente atrativo, os vagabundos se movem porque acham o mundo insuportavelmente inóspito. (BAUMAN, 1998, p. 117s.). 
Vagabundos são turistas involuntários, diz Bauman, como os romeiros da terra, os sem-terra, os desapropriados, os refugiados, etc. Gostaria de pensar que esta condição reflete em grande medida as buscas de turistas, viajantes, andarilhos e andantes dos tempos e espaços fragmentados, na busca por um sentido para viver.

\section{Conclusão}

Por que o ser humano coloca-se em movimento, seja peregrinações, seja no turismo? Segundo Bauman,

[...] em nossa sociedade pós-moderna, estamos todos - de uma forma ou de outra, no corpo e no espírito, aqui e agora ou no futuro antecipado, de bom ou de mau grado - em movimento; nenhum de nós pode estar certo/a de que adquiriu o direito a algum lugar uma vez por todas, e ninguém acha que sua permanência num lugar, para sempre, é uma perspectiva provável. Onde quer que nos aconteça parar estamos, pelo menos, parcialmente deslocados ou fora de lugar. (BAUMAN, 1998, p. 118).

Este artigo buscou indicar que a peregrinação e o turismo expressam a busca humana por um sentido maior, a experiência de um outro local ou uma vivência consigo mesmo, com um grupo de pessoas ou com o totalmente outro, o Transcendente, Deus, que auxiliam a viver e a voltar para o dia-a-dia contagiado por algo que rompe com a estrutura. Caminhar funciona como "retiro" e "escape" “das condições estruturais. Peregrinar proporciona um momento de verificação dos valores e axiomas essenciais da cultura, das instituições, das condições sociais e também da existência individual.

Em um mundo globalizado, marcado pela cultura consumista, os lugares em geral, também os lugares de peregrinação e os lugares de turismo, perdem seu conteúdo, sua memória, sua potencialidade de sentido e sua identidade. Pessoas passam pelos lugares, mas os lugares já não passam por elas. Com isso, o caminhar, em grande medida, perde também sua função liminar. Mesmo assim, a experiência de romper com o cotidiano, com o trabalho estressante, com o trânsito caótico, com 
a feiura dos lugares comuns e desordenados das nossas cidades e com tantos outros sintomas da falta de espaço e de lugar, é o que as peregrinações, o turismo ou até mesmo as simples caminhadas dominicais no parque mais ou menos proporcionam uma experiência de rompimento, um respiro, um sentido, algo de transcendência.

Peregrinações, como a Romaria da Terra, possibilitam, como uma autêntica communitas, a experiência de peregrinar, orar com os pés e, assim, redescobrir os lugares, símbolos, narrativas, mitos e tradições e dar-se conta de que somos parte deles. Elas possibilitam, acima de tudo, no limite, no liminóide, uma experiência consigo mesmo, de forma que aqueles que voltam já não são mais os mesmos que partiram. Fazer turismo, mesmo com toda a diferenciação existente, como uma experiência liminóide, também proporciona uma ruptura, mesmo que fragmentária, com a estrutura social e cultural na sua rigidez, obrigatoriedade, seus mecanicismos, controles, etc. Assim como nas Romarias da Terra, o turismo, de forma mais ou menos eficaz, proporciona uma experiência com um outro, com algo que os transcende, com um local-lá-fora, ao qual, de alguma maneira, pertencem, que seja, talvez a descoberta da condição de vagabundos em tempos e espaços pósmodernos.

\section{REFERÊNCIAS}

ADAM, Júlio Cézar. Liturgia com os pés: estudo sobre a função social do culto cristão. São Leopoldo: Sinodal/EST, 2012.

AUGÉ, M. Los no lugares: espacios del anonimato. 5. ed. Barcelona: Gedisa, 2000.

BAHR, Petra. Ritual und Ritualisation: Elemente zu einer Theorie des Rituals im Anschluss an Victor Turner. Praktische Theologie 33, Heft 2, p. 146, 1998.

BAUMAN, Zygmunt. O mal-estar da Pós-Modernidade. Rio de Janeiro: Zahar, 1998.

BOLLNOW, Otto F. Mensch und Raum. Stuttgart: Kohlhammer, 1963.

CLASTRES, Helène. Terra sem mal: o profetismo Tupi-Guarani. São Paulo: Brasiliense, 1978.

FREIRE, Paulo. Educação e mudança. 16. ed. São Paulo: Sal e Terra, 1979. 
JENNINGS JR; Theodore W. Rituelles Wissen. In: BELLIGER, Andréa; KRIEGER, David J. (Org.). Rithualtheorien: ein einführendes Handbuch. Opladen/Wiesbaden :Westdt. Verlag, 1998. p. 157-172.

MAY, Roy. Los pobres de la tierra: hacia una pastoral de la tierra. San José: DEI , 1986.

METTE, Norbert. Exclusão, um desafio prático-teológico e pastoral. Estudos

Teológicos, São Leopoldo, v. 50, n. 1, p. 69-81, jan./jun. 2010.

POST, Paul. Fields of the Sacred: Reframing Identities of Sacred Places. In: POST, Paul; MOLENDIJK, Arie L.; KROESEN, Justin E. A. Sacred Places in Modern Western Culture. Leuven/Paris/Walpole: Peeters, 2011.

POST, Paul; MOLENDIJK, Arie L; KROESEN, Justin E. A. Sacred Places in Modern Western Culture. Leuven/Paris/Walpole: Peeters, 2011.

RIVIÈRE, Claude. Os ritos profanos. Petrópolis: Vozes, 1996.

ROSA, Sandro da. Música e liminalidade: a experiência musical em contexto ritual e terapêutico. São Leopoldo/Quebec, 2017. (Tese de Doutorado) - Faculdades EST/Université Laval, 2017.

SOUZA, Marcelo Barros de; CARAVIAS, J. L. Theologie der Erde. Düsseldorf: Patmos, 1990.

STEIL, Carlos Aberto. O sertão das romarias: um estudo antropológico sobre o Santuário de Bom Jesus da Lapa - Bahia. Petrópolis: Vozes, 1996.

TUAN, Yi-Fu. Espaço e lugar: a perspectiva da experiência. São Paulo: Difel, 1983.

TURNER, Edith L. B. Prologue: from the Ndembu to Broadway. In: TURNER, Victor W.; TURNER, Edith L. B. On the edge of the bush: anthropology as experience.

Tucson/Ariz: University of Arizona Press. 1985. p. 1-15.

TURNER, Victor. Das Ritual: Struktur und Anti-Struktur. Frankfurt/New York: Campus Verlagp. 17, 51, 1989.

TURNER, Victor. The center out there: pilgrim's goal. History of Religions, Chicago: The University of Chicago Press, v. 12, n. 3, p. 191-230, 1973.

TURNER, Victor; TURNER, Edith. Image and Pilgrimage in Christian Culture. Nova York, Columbia University Press, 1978.

WESTHELLE, Vítor. Os sinais dos lugares: as dimensões esquecidas. In: DREHER, Martin (Org.). Peregrinação. São Leopoldo: Sinodal, 1990. p. 258-278.

YÁZIGI, Eduardo. To be or not to be: sobre o autêntico e o falsificado nas construções do turismo. Cultur - Revista de Cultura e Turismo, ano 03, n. 03, p. 1-36, junho/2009. 